\title{
LA PRESENCIA DEL FRANCÉS EN LOS LIBROS DE LA NOBLEZA MURCIANA DEL SIGLO XVIII
}

\author{
Amparo García Cuadrado* \\ Facultad de Comunicación y Documentación. Universidad de Murcia.
}

\begin{abstract}
Resumen: El objetivo de esta investigación es mostrar el grado de posesión de libros en idioma francés entre la nobleza de la ciudad de Murcia durante el siglo XVIII. Para ello se han revisado los inventarios post mortem y otros documentos protocolizados por esta elite durante el período comprendido entre 1700 a 1811. La muestra obtenida da buena cuenta de los impresos franceses en poder de dicho estamento social. Con estos datos se realiza un análisis cuantitativo y su distribución por materias según la naturaleza de los impresos. Los lectores se muestran más proclives a incorporar a sus colecciones impresos de contenido literario y lingüístico para el aprendizaje de la lengua gala, así como históricos y científicos en sentido amplio. Los resultados muestran un retrato porcentualmente pobre en su conjunto, caracterizado por una concentración de impresos en manos de unos pocos lectores, junto a la tardía incorporación de libros en francés.
\end{abstract}

Palabras clave: bibliotecas privadas en Murcia; bibliotecas nobiliarias; aprendizaje del francés; libros en francés; siglo XVIII.

\begin{abstract}
Title: THE PRESENCE OF FRENCH LANGUAGE IN MURCIAN NOBILITY BOOKS IN THE 18TH CENTURY.

Abstract: The aim of this research is to show the number of French books owned by the little Murcian nobility during the XVIII century. Regarding this fact, we have reviewed the post mortem inventories and other documents protocolized by this elite during the period between 1700 and 1811. The result displays the French prints owned by that social stratum. With this data, we make a cuantitative analisis of this prints and its distribution by subject matters based in their nature. The readers show themselves inclined to incorporate to their collections prints of literary and linguistic content for the learning of the Gallic language, as well as historic and cientific prints, broadly speaking. The results show a percentually poor portrait as a whole, characterised for a concentration of many printed documents for very few readers, along with the late onboarding of French books.

Keywords: private libraries in Murcia; noble libraries; French learning; books in French; 18th century.
\end{abstract}

Copyright: (C) 2021 Servicio de Publicaciones de la Universidad de Murcia (Spain). Este es un artículo de acceso abierto distribuido bajo los términos de la licencia Creative Commons Reconocimiento 4.0 Internacional (CC BY 4.0).

\section{INTRODUCCIÓN}

Durante el Setecientos hispano, igual que en el resto de Europa, la cultura francesa pasará a formar parte del universo ilustrado, razón por la que el conocimiento de su lengua "quedará unido a una cierta idea de progreso social y político" entre los círculos ilustrados, una aptitud que también alcanzará a la aristocracia (García Bascuñana, 2008, p. 74-75). Esta elite social mostrará una marcada francofilia que aparece reflejada en el contenido de sus bibliotecas. Los estudios publicados muestran con claridad la existencia de fondos franceses en una cuantía no despreciable, incluso en colecciones nobiliarias modestas (Arias de Saavedra, 2009, p. 35). Ahora bien, el interés por el aprendizaje del francés entre los nobles no era una novedad dieciochesca; con anterioridad, el advenimiento de determinados acontecimientos histórico-políticos en las relaciones entre ambos países provocaba la urgente necesidad de comprender y hablar el idioma galo. Así, el enlace de Felipe II con Isabel de Valois haría aparecer en el mercado la primera gramática francesa publicada en España con el título de Gramática con reglas muy provechosas y necesarias para aprender a leer y escribir la lengua francesa conferida con la castellana (Alcalá de Henares, 1565) del toledano Baltasar de Sotomayor, probablemente un profesor de francés llamado a la Corte para instruir a las damas y caballeros que debían de tratar a la joven reina. La dedicatoria del impreso no deja dudas sobre su utilidad en el desenvolvimiento cortesano, "pues uno de los mayores entretenimientos que entre ellos ay es el trato que con las damas se tiene, de las cuales muchas son francesas" (Suárez, 2008, p. 61-62). Además de señalar la conveniencia de aprender francés, reconocía Sotomayor que había otro idioma que por oportunidad política era importante en España: el italiano; la pertenencia a la Corona de territorios en donde se hablaba dicha lengua la hacían igualmente necesaria para el desenvolvimiento en la Corte (Gaspar, 2015, p. XLIX). Así pues, junto al francés, el italiano va a ser otra de las lenguas que, aún en el siglo XVIII, será conocida por la elite, quienes en buena parte habían adquirido prestigio, título y fortuna por sus desempeños en Italia al servicio de la monarquía. Por ello, no es excepcional encontrar libros en italiano en las bibliotecas particulares de las familias linajudas hispanas (Arias de Saavedra, 2009, p. 32-35). Por lo que a Murcia se refiere, lo hemos visto en la biblioteca del I marqués de Beniel, quien, tras servir en Italia y casar allí con una Gonzaga, pasaba a residir en la

\footnotetext{
*ampagar@um.es

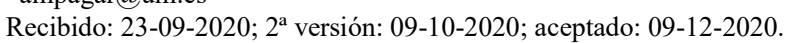

GARCÍA CUADRADO, A. La presencia del francés en los libros de la nobleza murciana del siglo XVIII. Anales de Documentación, 2021, vol. 24, nº 1. Disponible en: http://dx.doi.org/10.6018/analesdoc.445401. 
tierra de sus ancestros llevando consigo algunos libros en aquel idioma (García Cuadrado, 2017a, p. 421-457). Pero este no es el único caso que conocemos cuyas colecciones bibliográficas se encuentran jalonadas por impresos en italiano y que, incluso, algunas jóvenes se sintieran inclinadas a su estudio. Es el caso de dos hijas de la familia Paz y Galtero quienes recibieron clases de latín e italiano por parte de Vargas Ponce en 1796 durante los meses que el estudioso residió en la ciudad de Murcia y donde mantuvo relaciones con algunas familias del patriciado urbano (Abascal, 2010, p. 83).

Pero, ¿qué interés despertaba el aprendizaje de la lengua francesa durante la Centuria Ilustrada, cuál pudo ser su grado de conocimiento y el acopio de libros en francés entre la nobleza -titulada o no- de la capital murciana según se desprende del análisis de sus colecciones bibliográficas? Esta es la cuestión que pretendemos dibujar en estas páginas. Hace ya un tiempo comenzábamos a desbrozar los protocolos notariales de la Murcia del Setecientos con objeto de localizar los inventarios post-mortem que pudieran desvelar el grado de posesión de libros entre los distintos grupos socio-profesionales. En esta búsqueda, que abarca desde 1700 a 1811, fuimos centrando nuestra atención en las colecciones inventariadas de la nobleza, unas bibliotecas generalmente poco surtidas, pero no exentas de interés para establecer la panoplia de materias y autores leídos o, al menos, poseídos por la elite (Pedraza, 1999, p. 151), así como la presencia de libros en francés en sus estantes, sin desechar las traducciones de obras francesas tan abundantes en las lecturas de los españoles de entonces.

Es bien conocida la eficaz vía de penetración de la cultura imperante a través de las numerosas traducciones de libros franceses, particularmente si un mediocre dominio del idioma francés dificultaba su recepción al lector hispano; solo quien había logrado alcanzar un buen conocimiento de aquella lengua podía optar por las lecturas de moda en su versión original. Es lo que ocurre con personajes de la altura y formación de Jovellanos, cuya biblioteca políglota de 857 títulos en seis lenguas muestra una preferencia por los impresos en francés, con excepción de las obras en español, frente a las traducciones que son escasas (Aguilar, 1984b, p. 405-409). Este gusto del ilustrado asturiano por los originales franceses nada tiene que ver con el contenido de las bibliotecas murcianas por lo que ahora veremos.

Las fuentes que hemos utilizado para la extracción de datos han sido en su mayor parte los inventarios post mortem, antes citados, y/o las particiones de bienes entre los herederos, a las que hemos podido agregar los listados realizados con objeto de preservar los bienes de los hijos menores si el progenitor contraía un nuevo matrimonio. Hemos revisado, igualmente, las cartas de dote localizadas cuyo resultado por lo que a los libros se refiere es nulo. En total, han sido 77 las fuentes analizadas; de ellas, un $23 \%$ no presentan ni un solo libro entre sus cuantiosos bienes y de las que sí acogen colecciones bibliográficas tan solo el 18\% contienen impresos en francés, unos datos objetivos que vienen a confirmar la escasa penetración de las luces de la Ilustración en lengua francesa entre la pequeña nobleza urbana. Pero lo cierto es que este grupo social no fue ajeno a las corrientes culturales del momento pues su educación no era homogénea. Aquellos que habían estado en contacto o se habían formado en los Seminarios de Nobles o en el Colegio-Seminario de San Fulgencio (Viñao, 1986), habían pasado por los centros militares e ingresado en el Ejército, o contaban con estudios universitarios pudieron ser focos de irradiación de las ideas ilustradas entre los de su clase como bien señala Pérez Picazo (1988, p. 491-492), quien analiza sucintamente dos colecciones bibliográficas del patriciado urbano de finales de la centuria.

No existen en la actualidad otros trabajos sobre bibliotecas nobiliarias de la ciudad de Murcia salvo la del académico Rejón de Silva (Peña, 1985) y las cuatro recogidas en dos artículos más recientes (García Cuadrado, 2017a y b), donde la presencia de fondos en francés no es significativa. Pese a ello, parecía de interés mostrar en estas páginas una muestra más amplia y suficientemente representativa de la influencia que la modernidad ilustrada y su recepción podía haber tenido en dicha elite mediante el elenco de autores y títulos en francés de sus bibliotecas.

Los porcentajes obtenidos han contado con las consabidas carencias propias de la mayoría de estos listados, pero que conviene reseñar en este caso. En primer lugar, la presencia de lo que V. Infantes califica de "biblioteca devaluada" al carecer de la mínima descripción de los impresos que la constituían (Infantes, 1997, p. 287). Así, podemos encontrar desde "un libro en francés" a "una porción de libros en un arcón", si bien lo más común son aquellas descripciones que se ciñen a un recuento cuantitativo. A modo de ejemplo, el inventario de la colección no escasa de don Francisco Vicente de Paz y de su esposa doña Isabel de Valcárcel fue descrita en 1759 en los siguientes términos:

Habiendo visto y reconocido un estante de libros de ziento catorce grandes y pequeños, de vidas de santos, ystorias, y diferentes papeles de música, que hai en un cajón de dicho estante; como también nueve libros de comedias, que según su estado y postura los regula y tasa todo ello mill quatrozientos y zinquenta reales de vellón. ${ }^{l}$ 
Por suerte, en 1773 la colección sí fue desmenuzada a la muerte de doña Isabel. ${ }^{2}$ En esta forma, aunque algo mermada -de 123 títulos quedaban 105-, podemos saber de la presencia de varios impresos para el aprendizaje del francés, probablemente ya presentes en vida del esposo. Peor suerte hemos tenido al abordar el inventario de bienes realizado en 1714 por la I condesa de Montealegre al matrimoniar, en segundas nupcias, con don Antonio Montolíu; aquí contamos con "ziento y ochenta libros, grandes, medianos y pequeños, y espirituales en dos estantes nuevos". 3 Caso similar, aunque con alguna pista, lo encontramos en los "ciento y quarenta libros de a folio, medio folio y de a quartilla, de doctrina christiana, historia, poesía, lengua extrangera, con diferentes títulos" en poder de la viuda del caballero santiaguista Antonio de Rueda Marín, doña Inés Melchora Chillerón en 1752. ${ }^{4}$ A esta especie se ha sumado aquella donde las bibliotecas se encuentran parcialmente devaluadas. Tal vez el caso más significativo sea el de la colección de don Juan Francisco Carrillo de Albornoz en 1757. Tras dar razón de 14 títulos de los 155 libros hallados en "un armario cerrado con las puertas de arambre y el tercio de abajo con puertas de madera", el escribano se limita a señalar formatos, encuadernaciones y precios del resto de la colección. ${ }^{5}$ Afortunadamente, entre los pocos libros descritos, se anota el Diccionario de Sobrino, lo que nos deja con el convencimiento de que el francés tendría cierta presencia en la biblioteca. En segundo término, la identificación de impresos de nuestro interés ha contado a veces con un obstáculo insalvable al tratar de designar la autoría de varias gramáticas francesas. Una tercera dificultad, no menos importante, surge cuando el escribano olvidó hacer constar que tal o cual título estaba en lengua francesa. En estas escasas ocasiones, la fecha del inventario, más la indicación del formato y el número de tomos han venido a confirmar con bastante seguridad el idioma del ejemplar. A todo esto, debemos considerar los posibles casos de "bibliotecas clandestinas", aquellos libros prohibidos que por razones obvias no podían figurar en los inventarios (Pedraza, 1999, p. 149), pero que existían en ciertos círculos ilustrados de la Murcia finisecular y que fueron delatados a la Inquisición (Viñao, 1986, p. 25-32).

Como podemos ver, la casuística es muy variada y, pese a las limitaciones señaladas, intentaremos mostrar la presencia del francés, un dato sin duda de gran interés para ayudar a evaluar el grado de conocimiento de este idioma entre las familias de elite murciana y el interés que irá adquiriendo paulatinamente en la segunda mitad del siglo XVIII.

\section{AUTORES FRANCESES EN LOS LIBROS DE LA ELITE}

Antes de centrarnos en los impresos en francés, veamos grosso modo la presencia de unos cuantos autores que, de manera bastante constante, formaban parte de las colecciones de este grupo social. En estas los autores franceses traducidos es apenas perceptible en los primeros cuarenta años, donde tan solo un espiritual francés y un jesuita formaban parte de las lecturas piadosas de la nobleza: san Francisco de Sales con su Introducción a la vida devota desde 1706 y Nicolás Caussin desde 1710 con La jornada del christiano y La Corte Santa. Fuera del ámbito religioso, el primer autor recogido en los listados es François-Antoine Pomey con su Panteón mítico en latín. En la década de los veinte, la presencia de lo francés se amplía con los jesuitas Boutauld Consejos de la sabiduría: recopilación de las maximas de Salomon, Pierre Gautruche con sus Historia poetica e Historia sagrada, Reflexiones Christianas y el padre François Nepueu Pensamientos o reflexiones christianas, para finalizar con el benedictino Duplessis con la Historia de Jacobo II.

Nada más iniciada la década de los años cincuenta, las obras francesas se incrementan en materia religiosa e irrumpe con fuerza la Historia. Entre las primeras, el Tratado de la confianza en la misericordia de Dios del obispo Languet, la Historia del pueblo de Dios del jesuita Berruyer y los Pensamientos cristianos del también jesuita Bouhours. Pero el más celebrado de todos será Claude Fleury con su famoso Catecismo histórico, traducido por Interián de Ayala en 1718, y las Costumbres de los Israelitas y de los cristianos puestas en castellano por el bibliotecario real Martínez Pingarrón en 1737. También la Historia de las variaciones de las Iglesias protestantes del obispo Bossuet forma parte de las colecciones analizadas con bastante asiduidad.

Dentro de la historia civil son las biografías las que mayor protagonismo adquieren en las bibliotecas de los murcianos. Además del ya citado Duplessis, puntualmente aparece Gustave Adlerfeld con su Historia de Carlos XII Rey de Suecia, mientras que Massuet tiene mayor protagonismo por la Vida del duque de Riperda y en menor medida con la Historia de la última guerra. Por su lado, Esprit Flechier es uno de los más citados en los inventarios con la Historia del Cardenal Cisneros, escrita por el obispo francés en 1693, un buen exponente de la admiración que la Francia de Luis XIV sentía por el insigne prelado (Pérez, 2014, p. 270). La obra sería muchas veces reeditada y traducida a varios idiomas que extenderían la fama del cardenal por toda Europa. Su lectura en España fue temprana gracias a la traducción realizada por Franco de Villalba en Zaragoza (1696). El heroe español: historia del emperador Teodosio el Grande es otro de los títulos de Flechier, un espejo para la educación del delfín, conocido por la elite gracias a la versión realizada por el padre Isla en 1731; aunque dirigida al gran público por los editores, la traducción 
del jesuita no alcanzó el éxito esperado si se compara con la del Compendio de Historia de España de Duchesne, según tenemos constatado en el caso murciano (Llanos, 1999, p. 336-337). Un nombre que menudea en los listados es el gran pedagogo filojansenista Charles Rollin, particularmente por su Historia antigua compendiada por Francisco Javier de Villanueva en numerosos tomos que irán apareciendo en el mercado español desde 1755 (Medina, 1999 , p. 234-235).

Con la llegada de los sesenta la nómina de traducciones del francés se amplía entre nuestros lectores y entran en escena el Estado político de la Europa, el Comercio de Holanda de Pierre-Daniel Huet, puesto en castellano por el marqués de Belzunce, y el Discurso sobre la Historia universal de Bossuet dirigido al delfín de Francia, que será traducido en 1728 y circulará sin obstáculo por España a lo largo de todo el siglo XVIII (Lépinette, 2003b, p. 76). Son años en que encontramos a Fénelon con su Telemaco, junto a la Escuela de príncipes y caballeros del señor de La Mote Levayer, obra dirigida a la educación de su tutelado el duque de Orleans, hermano menor de Luis XIV.

Las bibliotecas analizadas, cuyos dueños fallecieron en el último tercio de la centuria, muestran una interesante evolución hacia la modernidad ilustrada por lo que a traducciones francesas se refiere. Son fundamentalmente dos las notas que van a caracterizar estas colecciones. En primer término, vemos aparecer en los inventarios nombres femeninos entre los autores citados. En 1788 la marquesa viuda de Espinardo contaba entre sus libros con dos obras de madame Le Prince de Beaumont: las Conversaciones familiares y el Almacen y biblioteca completa de los niños. La primera de ellas salió traducida en España en 1773 y su buena acogida conduciría a la traducción del Almacén, que vería la luz en castellano en 1778. Dado el carácter instructivo y moral de sus escritos, sus obras serían utilizadas como libros de lectura y enseñanza para niños de ambos sexos (Bolufer, 2002, p. 37-38). También los Cuentos morales (1797) y las Memorias de la Baronesa de Bateville (1795) de la misma autora fueron adquiridos por otra de las familias del patriciado, así como los Días alegres de madame Gomez estampado por la Imprenta Real entre 17921797. De otra fémina, Luisa de la Misericordia, son los Sentimientos, afectos y conversion de un alma a Dios; la obrita de la antigua duquesa de La Vallière y amante de Luis XIV se encontraba frecuentemente en los estantes, aunque sin alcanzar los niveles del Año christiano de Jean Croisset, el Catecismo histórico de Fleury o la Última despedida de la Mariscala a sus hijos del marqués de Caracciolo, títulos cuyo recorrido entre las clases privilegiadas se extenderá al siglo XIX. En segundo lugar, se observa la presencia de ciertos autores que ayudaron a difundir las ciencias como el abate Pluche con el Espectáculo de la Naturaleza y su complemento Historia del cielo, dos obras de gran permanencia en las colecciones. De manera más ocasional encontramos a Sigaud de la Fond, difusor de la física moderna mediante sus Elementos de física teórica y experimental (Rider, 1990, p. 145-146), y Chevigni con la Ciencia para las personas de corte, espada y toga, impreso de carácter divulgativo y didáctico traducido, adicionado y publicado en Valencia en 1729 por Juan Bautista Company. También los volúmenes inconclusos de la Encyclopedia metódica, impresa en Madrid por Sancha (1788-1794), fueron adquiridos por los lectores más ilustrados, quienes prefirieron la traducción española a la versión francesa ofrecida por Panckouche a los españoles a través de su agente en Madrid, Thévin (Jalón, 1997, p. 115).

Ocasionalmente vemos desfilar otros nombres franceses dentro de la disciplina histórica. Tal es el caso de Millot por sus Elementos de historia universal, el de Pierre Charpentier de Longchamps por la Historia de la última guerra entre la Inglaterra, los abates Lenglet (Principios de la Historia para la educación de la juventud e Historia universal), y Vertot (Historia de las revoluciones), junto a un voluminoso Diccionario histórico, el de Moreri, una de las obras de referencia más populares entre nuestros lectores pese al elevado coste de sus muchos tomos.

Por su parte la panoplia de autores religiosos se amplía con tres nuevos títulos de Nicolás Jazmín (Verdadero antidoto contra los malos libros, Historia de las fiestas de la Iglesia y Plácido a Escolástica). Del exégeta benedictino Calmet se leía la Historia del Antiguo y Nuevo Testamento y del jesuita Lallemant su edición de los Salmos de David; la Biblia latina anotada por Du-Hamel, los catecismos de Pouget y de Bossuet, los sermones de Girout y los de Burdalue, etc. formaban parte de algunas colecciones donde el universo religioso ocupa un puesto destacado frente a otros intereses lectores.

Muy interesante, por su excepcionalidad, resulta el análisis de los libros franceses traducidos que conformaban la gran colección de don Joaquín Saurín, hombre preocupado por los métodos y tratados de estudio dirigidos a la juventud. En sus anaqueles se encontraban autores tan destacados como Condillac (Lógica), Diderot (Proyecto sobre la educacion publica), Racine (Atalía), Buffier (Historia universal), Fénelon (Dialogo de los muertos), Fleury (Elección y métodos de estudio) o Boileau (Sátiras). Poseía, entre otros impresos, el Proyecto sobre educación pública puesto en español por Jaime de Abreu (1767), La urbanidad y cortesia universal de Caillers, las Memorias literarias de París traducidas por Luzán, y las Memorias para la historia de las ciencias y artes: que se empezaron a imprimir año de 1701 en Trevoux. Y como hombre preocupado por la Epigrafía y la Numismática disponía del Diarium italicum sive Monumentorum veterum, bibliothecarum, musaeorum del maurista Bernardo de Montfaucon (Paris, 
1702), la Historia de las medallas o introducción al conocimiento de esta ciencia escrita en francés por Carlos Patin y de Jean Foy Vaillant la Numismata imperatorum Romanorum (Amsterdam' 1700). ${ }^{6}$

\section{EL APRENDIZAJE DEL FRANCÉS: GRAMÁTICAS Y DICCIONARIOS}

Iniciamos nuestro recorrido por los libros en francés con aquellos títulos destinados al aprendizaje de dicha lengua: gramáticas y diccionarios. Por lo que a los segundos se refiere, la preferencia por el compuesto por Francisco Sobrino es absoluta. Este Maestro de Lengua Española en la Corte de Luis XIV dará a las prensas el Dictionnaire nouveau des langues françoise et espagnole el mejor y más copioso de los editados hasta el momento donde el lector podía encontrar en sus dos partes "la explicación del Español en Francés y del Francés en Español", valiéndose para ello de "graves Autores Españoles" (Covarrubias, Saavedra, Quevedo o Gracián) y franceses (Furetière, Tachard, Richelet, Danet). Editado en Bruselas por Foppens, con elegantes frontispicios en sus dos tomos, fue reimpreso frecuentemente en Bruselas por el mismo Foppens y más tarde por Gosse \& Compañía, en Amberes por Piestre \& Delamolliere y en Lyon por este último a lo largo del siglo XVIII. Como su propio autor también publicitaba, se trataba de un diccionario que servía para todos los que quisieren aprender cualquiera de las dos lenguas; "la Española a los que supieren la Francesa y esta a los que entendieren la Española", si bien iba dirigido fundamentalmente a un público francoparlante (Supiot, 1991, p. 497-498). Aunque ignoramos cuáles fueron las ediciones manejadas por los lectores murcianos, sí sabemos de su popularidad ya que el 63\% de las bibliotecas provistas de libros en francés disfrutaban del mismo. En este punto, la elite murciana seguía los dictados de la moda imperante pues "el Sobrino", como vulgarmente era conocido, gozó de gran éxito desde su primera edición en 1705 pese a los cuantiosos préstamos tomados del Tesoro del más importante lexicógrafo del XVII, el hispanista César Oudin (Zuili, 2016, p. 238). Precisamente, en los ricos anaqueles del murciano don Gil Francisco de Molina y Junterón se encontraba en 1727 el Thresor des trois langues, espagnole, françoise, et italienne, otro conocido plagio de la obra de Oudin realizado por el francés Hierosme Victor del que se conocen seis ediciones entre 1609-1671; en este diccionario trilingüe el autor "copió íntegramente el contenido de la edición parisina de 1607 del Tesoro [...] de César Oudin, introdujo muchas entradas suplementarias", más la traducción italiana de todos los vocablos (Zuili, 2016, p. 275). La nómina de impresos lexicográficos se amplía con un "Vocabulaire François", cuya autoría desconocemos, y el titulado Synonymes françois: leurs différentes significations et le choix qu,il en faut faire pour parler avec justesse del abate Girard, ambos en manos del ilustrado don Antonio Rejón de Silva, madrileño de ascendencia murciana y cuyos últimos años de vida discurrieron activamente en la capital del Segura como socio de la Económica de Amigos del País. No cabe duda de que Rejón dominaba el francés, idioma que utilizó para el aprendizaje del inglés mediante un "Dictionaire Anglois a Franzois" e incluso una "Gramática inglesa y francesa", impresos anotados en el inventario de su biblioteca (Peña, 1985, p. 113134, apéndice III).

Curioso puede resultar conocer el coste económico asignado a los diccionarios una vez tasadas las bibliotecas a la muerte de sus propietarios. Así vemos que "el Sobrino" suele oscilar entre los 180 reales del ejemplar en pasta de los II condes del Valle de San Juan (1749) y los 20 del que andaba en poder de los Carrillo de Albornoz en 1757, pasando por los 50 y 60 reales en que fueron tasados los dos tomos del conservado por el III marqués de Torre-Pacheco (1781) y por la viuda doña Isabel Valcárcel (1773), respectivamente. A finales de siglo, otros dos personajes de la elite disponían de sendos ejemplares del Sobrino aumentado o Nuevo Diccionario de las lenguas española, francesa y latina editado por François Cormon (Amberes: Hermanos Tournes, 1769) en tres tomos, ejemplares que fueron valorados en 140 reales en pasta y en 60, probablemente al estar dotado de una peor encuadernación.

Junto a estos diccionarios encontramos los manuales de gramática francesa, otro elemento imprescindible del aprendizaje como indica el elenco de títulos y métodos estampados por los talleres hispanos durante el siglo XVIII, que superan ampliamente la veintena sin contar sus reediciones (Supiot, 1996, p. 313-329). Los murcianos que poseían una de ellas, normalmente, contaban también con su correspondiente diccionario y algún que otro título que manifiesta la utilización de ese idioma en sus relaciones sociales. Eso es lo que nos sugiere los Diálogos en español y francés de Francisco Sobrino, estampados por primera vez en 1708, copia mejorada de los publicados por César Oudin en $1605^{7}$ (Zuili, 2006, p. 284-285). Como explica Arribas (2010, p. 26 y 29), este género de impresos, que fueron en principio publicados como parte integrantes de gramáticas y diccionarios, pasarán a ser vendidos como volúmenes independientes, reeditados y plagiados para el aprendizaje de una segunda lengua per usum. A los Diálogos se suma otro texto de carácter funcional, el Secretario español enseñando la manera de escrivir cartas españolas (...) explicadas en Francès (Foppens, 1720), la obra más original del programa docente de Sobrino, un formulario de cartas francesas que por su carácter bilingüe podían ser también de gran utilidad a los españoles (Suárez, 2008, p. 119). Ambos títulos estampados en $8^{\circ}$ y encuadernados en pasta española paraban en manos de los condes del Valle de San Juan a mediados de siglo, aunque procedían -igual que el Sobrino- del lote de libros llevados a su segundo matrimonio por doña María Ana de Roda Caltellví, la condesa, en $1743 .^{8}$ 
Centrándonos ya en las gramáticas, en los estantes de los mismos aristócratas se hallaba impresa en dos tomos la que compuso Juan Enrique Le Galois, ingeniero militar francés establecido en España, titulada Nueva Gramática Francesa con Nuevo Methodo para aprender a pronunciar, aparecida en Pamplona en 1747, lugar de residencia de su autor (Suárez, 2008, p. 125-127). El impreso, que debió de ser adquirido poco antes de la muerte de la condesa en febrero de 1749, no estaba solo pues en el mismo armario de la alcoba principal paraban otros "dos tomos en pasta, viejos, de la lengua francesa en ocho reales vellón" de imposible identificación. ${ }^{9}$

En los años 70 la viuda de don Francisco Vicente de Paz, Isabel de Valcárcel, tenía entre sus ejemplares "una gramática francesa" más otra del padre Núñez (Gramática de la Lengua Francesa) e, incluso, unas "porciones" de aquella, sin duda las Adiciones a la Gramática Francesa, que compuso el R.P. Núñez, para el uso del Real Seminario de Nobles dispuestas por Antonio Galmace (Madrid, 1745), un complemento a la gramática más conocida de su tiempo (Viémon, 2013, p. 514). La popularidad del texto del jesuita Núñez de Prado sería objeto de numerosas ediciones desde la primera madrileña de 1728; hemos rastreado hasta nueve ediciones a lo largo del siglo sin contar las citadas Adiciones. Curiosamente, andando el tiempo, sería objeto de rechazo por parte de la autoridad inquisitorial. De los años noventa hemos localizado una nota manuscrita tras los preliminares de un ejemplar de la edición costeada por la Compañía de Impresores y Libreros en $1791 .{ }^{10}$ Un acerado censor granadino descalifica en ella las aprobaciones vertidas en sus correspondientes informes (1728) por los jesuitas padre Alberto Pueyo, calificador de la Inquisición, y el padre Campo Verde, rector del Real Seminario de Nobles y catedrático de Prima de la Universidad de Alcalá: "Y yo, el infrascrito, juzgo que merece ser condenada al fuego contra el dictamen del P. Pueyo y del P. Campo Verde. Fr. Simon de Carlos Inquisidor de Granada”. Pese a la drástica postura del censor, la gramática formaba parte de los fondos de la elite. Con seguridad pudieron disfrutar de ella la familia de doña Isabel de Valcárcel y don Joaquín Saurín, distinguido miembro de la Económica de Murcia; el segundo disponía a su muerte (1790) de dos ejemplares. La falta de datos concretos nos impide conocer la autoría de otros ítems de "grammatica francesa" inventariados, aunque no podemos descartar que se trate de la misma, ejemplares que bien pudieron ser manejados también para la formación de los hijos de las familias aristocráticas como los Fontes Riquelme (García Cuadrado, 2017b, p. 399) o los marqueses de Torre Pacheco. ${ }^{11}$ No debemos olvidar la importancia que el aprendizaje de lenguas, en particular la francesa, tenía en los planes de estudios de los centros educativos destinados a la clase dirigente. Una mirada a las Constituciones del Seminario de Nobles fundado en Madrid en 1725 por Felipe V da buena cuenta de lo dicho en su punto 3: "El fin menos principal, aunque principal también, es, que se instruyan en aquellas Facultades y Ciencias, que más adornan à la Nobleza, como son: la Grammatica, la Rhetorica, la Poesia, las Lenguas, Francesa, Italiana y Griega".

Las informaciones de que disponemos sobre la trayectoria vital/educativa del patriciado murciano señalan que unas pocas familias principales optaron por educar a sus retoños en las aulas de la institución madrileña, alumnado para quien iba destinado el manual del jesuita. Según los datos que arroja el estudio acerca de la procedencia geográfica de los alumnos de la real institución, el cómputo para Murcia es escaso y su cuantía irá decreciendo a lo largo del siglo (Chaparro, 2013, p. 9, cuadro 2). Si durante el período comprendido entre 1727-1754 el número de alumnos murcianos se eleva a 13, la suma desciende a 4 durante el periodo de 1785-1808. Naturalmente la existencia de otro Seminario de Nobles, el de San Pablo, en el limítrofe reino de Valencia, iría en detrimento de los estudios madrileños. La asistencia al real establecimiento de la ciudad del Turia, que exigía igualmente el aprendizaje del idioma de moda, la tenemos documentada para los vástagos de los Melgarejo y Mergelina, los Molina, los Vera Saurín, marqueses de Espinardo y los Flores (Ruiz, 1980, p. 117-134).

El caso es que la reconocida gramática de Núñez de Prado, “el primer gran manual de francés para españoles del siglo XVIII" como lo califica García Bascuñana (2005, p. 136), presentaba algunas carencias que trató de solventar Antonio Galmace, otro maestro de lengua francesa en la Corte, con el empleo de la pronunciación figurada en sus Adiciones, una novedad para España en esta clase de manuales (Gómez, 2008, p. 122-124). El propio Galmace daría prontamente a la imprenta otro manual de enorme éxito, la Llave nueva, y universal, para aprender con brevedad, y perfección la Lengua Francesa (Madrid, 1748), una ampliación de sus Adiciones, cuyo privilegio de impresión en exclusiva por diez años no pareció suficiente para evitar las impresiones fraudulentas que se esperaban. De hecho, Galmace firmará cada uno de los ejemplares de la tirada para tratar de poner freno a la puesta en el mercado de otras impresiones que trasgrediesen el privilegio de impresión y venta en su poder. ${ }^{12}$ Pese a las críticas vertidas por PierreNicolas Chantreau al método de Galmace, la Llave nueva sería objeto de una gran aceptación a tenor de las reiteradas ediciones madrileñas y parisinas con destino al lector hispano. La obrita, uno de los métodos más completos publicados hasta la fecha, paraba entre los libros del ya citado Saurín y Robles, y fue solicitada reiteradas veces, entre otros impresos de surtido, por los libreros Benedicto de Murcia y Cartagena a sus proveedores barceloneses Piferrer, desde 1790 a $1804 .^{13}$ 
Gramáticas y diccionarios no eran los únicos instrumentos de aprendizaje que surtían las colecciones de la época. El Telémaco será una tercera herramienta para abordar el estudio del francés durante el período, si bien solo uno de nuestros lectores más formados, Saurín y Robles, lo había incorporado a su biblioteca en francés. Las Aventures de Télémaque (1699) de Fénelon sería una lectura obligada en los planes de estudio de la nobleza por su carácter moralizante y pedagógico al tratarse de una novela histórica destinada a una lectura de entretenimiento, al tiempo que permitía una iniciación en conocimientos tales como la Historia antigua, la Mitología y la Geografía (Lépinette, 2003a, p. 102, como se citó en García Bascuñana, 2015, p. 282). La tardía versión española de la obra del obispo de Cambrai -sale a luz en La Haya en 1713- no sería obstáculo para su exitosa recepción en la España dieciochesca y parte del siglo XIX. Pese al recelo mostrado por la Inquisición y la censura de los pasajes más comprometidos (1771), el Santo Tribunal "no pudo impedir que el Telémaco, utilizando como coartada sus valores pedagógicos y didácticos, se convirtiera en libro de lectura constante y obligada", y fuera habitual su presencia en los anaqueles de la elite (García Bascuñana, 2015, p. 278). Nada tiene de extraño, por tanto, que una lectura de algunos de los certámenes celebrados cada dos años por los alumnos del Seminario de Nobles muestre con claridad la utilidad que la obra de Fénelon y las de otros autores franceses tenían en el aprendizaje de los jóvenes. Así, por ejemplo, en los Exercicios literarios de 1788 el alumno debía mostrar su adelanto en la lengua del país vecino con la lectura en francés y su traducción de un fragmento de las Aventuras de Telémaco y las Oraciones fúnebres de Fletchier para acreditar su inteligencia en esa lengua, además de escribir cartas francesas, entre otras ejercitaciones. Lo cierto es que, bien fuera por vía educativa o porque la presencia de la obra de Fénelon prestigiaba toda colección privada, su incorporación en las bibliotecas murcianas es un hecho, si bien escaso y tardío; solo el 7,5\% contaba con un ejemplar y siempre en colecciones inventariadas en la segunda mitad del Setecientos.

\section{LOS IMPRESOS EN FRANCÉS}

Veamos ahora qué tipo de impresos en esta lengua conformaban el pequeño porcentaje presente en las colecciones privadas que venimos analizando. El primero de los libros computados estaba en poder de los marqueses de Beniel en 1710, aunque el grueso de los impresos se localiza ya en los años finales, particularmente, en los inventarios de los patricios más ilustrados. Este hecho vendría a confirmar la tardía expansión del francés entre la elite murciana frente al italiano, idioma más visible desde épocas tempranas ${ }^{14}$. Por otra parte, aquellas bibliotecas con materiales al servicio del aprendizaje del francés rara vez presentan más de tres impresos en aquel idioma. El monto total de títulos distintos, no de ejemplares, localizados es pequeño pues tan solo llega a 61, títulos que podemos agrupar por su contenido en cinco grandes campos temáticos: Religión, Letras, Historia (se incluye la Geografía), Ciencias (Filosofía, Física, Ciencia Militar, Política...) y Educación. Desde el punto de vista porcentual, la materia mejor representada son las Letras (Lengua y Literatura) con cerca del 46\%, seguida de la Historia que alcanza el $18 \%$ y las Ciencias con un $14,7 \%$ del total; la materia Religión ocupa el 8,1\% y la Educación un elevado 13,2\%. Examinemos ahora los títulos que conforman cada una de estas materias, donde haremos constar la fecha de la primera edición de que tengamos noticia ante la dificultad de concretar la edición inventariada. ${ }^{15}$

Letras (46\%). Como ya se ha visto es el campo temático más amplio donde su porcentaje se distribuye por igual entre la Lengua y la Literatura. Dejando de lado los títulos de la sub-materia Lengua ya expuestos, abordemos ahora los impresos literarios. Entre ellos encontramos cuatro títulos con diversidad de volúmenes en pequeño formato con las Oeuvres de monsieur de Saint-Evremond (Londres, 1706), uno de los pocos franceses de su tiempo que, alejado de la moda del siglo XVII, enjuició positivamente la literatura española en sus obras (Esquerra, 1936, p. 353-363). A esta se suman tres tomos en dozavo con las Oeuvres de M. Thomas de l,académie françoise (Amsterdam, 1773-74), autor con el que contaba también la biblioteca de Jovellanos aunque en dos volúmenes en $8^{\mathrm{a}}$ (Oeuvres diverses. Amsterdam, 1768) (Aguilar, 1984a, p. 94). El académico francés sería traducido solo parcialmente al castellano pese a la estimación que su actividad intelectual despertara a lo largo del siglo entre sus compatriotas. En tercer lugar, se anotan con seis tomos las Oeuvres du marquis de Caracciolo (Breslaw de 1756) de indudable éxito en Europa. La recepción de Caracciolo en España correría a cargo de Francisco Mariano Nifo, quien a partir de 1774 iniciaba la traducción de sus libros con destino a un público ortodoxo desde una perspectiva religiosa, pero moderno y, por tanto, muy en consonancia con las directrices gubernamentales de la época carolina (Álvarez, 2014, p. 102-103). El último título de esta especie son las Oeuvres complettes d,Alexandre Pope, editadas en París en 1789 en ocho tomos $8^{\circ}$; sus poemas solo verán la luz traducidos al español en el siglo XIX, de ahí la escasa difusión de sus obras en la España ilustrada. Por su parte la voluminosa teoría literaria del abate Charles Batteux, contenida en el Cours de Belles-lettres ou Principes de la litterature (Paris, 1753), hubo de ser leída en su versión original, pues los principios generales de poética y retórica del académico y profesor real no fueron traducidos hasta finales de siglo por García de Arrieta, nueve volúmenes estampados por las prensas de Sancha entre 1797 a 1805, y que sería utilizado como libro de texto a inicio del Ochocientos en el sevillano Colegio de Humanidades (Aguilar, 1988, p. 242). Las obras de los clásicos están presentes en el Dictionnaire pour l,intelligence des auteurs classiques, grecs et latins, tant sacrés que profanes de 
François Sabbathier (Paris, 1766-89). Estamos ante una obra de referencia de notable extensión, aunque solo fueron adquiridos alguno de sus tomos por parte del académico Rejón de Silva. Lo mismo sucede con Le theatre des grecs del pedagogo jesuita padre Brumoy (Paris, 1730) en poder de Saurín y Robles en 1790. El trabajo del jesuita iba encaminado a divulgar en su totalidad un teatro que, según su opinión, había sido poco estimado e incluso mal juzgado hasta el momento (Bastin-Hammou, 2010, p. 27-41). En los mismos estantes se encontraban las Philippiques de Demosthene (Paris, 1701) precedidas de un extenso prefacio histórico de Jacques de Tourreil, otro miembro de la Academia Francesa.

Interesante resulta la presencia de Les principales aventures de l,admirable Don Quichotte représentées en figures elaboradas por hábiles artistas, obra que sería varias veces impresa. Conocemos una edición estampada en La Haya (1774) en $8^{\circ}$ en dos volúmenes y otras dos en $4^{\circ}$ en uno (La Haya 1746 y Lieja, 1776), la última engalanada con orla tipográfica en todas sus páginas y con 31 grabados calcográficos de las aventuras quijotescas, probablemente la edición adquirida por los lectores murcianos. La literatura de entretenimiento está representada por Gayot de Pitaval, abogado del Parlamento parisino, autor de L,art d,orner l, esprit en l,amusant ou Nouveau choix de traits vifs saillans \& legers soit en ves, soit en prose (Paris, 1728), y las Lettres nouvelles del dramaturgo y novelista del siglo XVII Edmé Boursault, acompañadas de fábulas, comentarios y otras particularidades "tan agradables como útiles" (Paris, 1697). Finalmente encontramos las Fables hérö̈ques de Audin con discursos históricos del que fuera secretario de Felipe V, Bruzen de la Martinière (Amsterdam, 1720), obra destinada al Príncipe de Asturias y engalanada con alegóricos grabados calcográficos.

Historia (18\%). En el campo histórico/geográfico la incorporación de ejemplares a las bibliotecas privadas murcianas se inicia en época temprana con una valiosa obra geográfica: "cinco libros pequeños con encuadernación de tablas doradas", impresos en Amberes en francés, con la descripción del universo; sin duda un atlas, cuya autoría y fecha de publicación no podemos identificar con total certeza. Tal vez se trate de la Description de l,univers de Allain Manesson Mallet, aunque desconocemos la edición antuerpiense que volvemos a encontrar citada en el inventario del difunto marqués de Beniel en 1727. Otro impreso geográfico es la Grammaire geographique ou Analise exacte et courte du corps entier de la geographie moderne (Paris, 1748), traducción francesa de la obra de Patrick Gordon, geógrafo inglés y autor del Thesaurus geographicus publicado en 1693.

El listado histórico propiamente dicho principia con La politique du cardinal Portocarrero decouverte (Madrid, 1709), ejemplar en $12^{\circ}$ encuadernado en pasta en manos del marqués del Villar en 1765 . El librito, con pie de imprenta falso -había sido estampado en Holanda- será prohibido por el Santo Oficio por Edicto de marzo de 1756 (Rubín, 1790, p. 213). El resto de los impresos históricos pertenecen a colecciones de los últimos años de la centuria dieciochesca. En ellas se localiza una traducción del original inglés Introduction a l,histoire d,Angleterre (Amsterdam, 1695) del ensayista y político Willians Temple. Sobre historia de la Iglesia se citan Los Principes de l,Histoire pour l,Education de la jeunesse par Années \& par Leçons: sixieme année; Histoire de l'Eglise del abate Langlet du Fresnoy (Amsterdan, 1736-39), seis tomitos en $12^{\circ}$ de marcado carácter didáctico, como también lo eran los dos tomos del Abrégé de l,histoire sacrée et profane (Amsterdam, 1771), en francés y latín, destinado al aprendizaje de la lengua latina y provisto de finas láminas. La Antigüedad clásica está presente con las Lettres a Monsieur Bailly sur l,histoire primitive de la Grece de Rabaut de Saint-Etienne (Paris, 1787). Saurín y Robles contaba con las Lettres du Cardinal Mazarin: Où l,on voit Le Secret de la Négociation de la Paix des Pirene,es (Amsterdam, 1746), acontecimiento histórico de gran relevancia en las complejas relaciones entre ambos países en el siglo XVII. En la misma biblioteca se hallaban los quince tomos en latín y francés de L, Antiquité expliquée, et representée en figures de Bernard de Montfaucon (Paris, 1719-1724), una voluminosa y cara obra de referencia tasada en 1.500 reales que no podía faltar en los anaqueles de un estudioso de las antigüedades como era don Joaquín Saurín. En ella se localiza, igualmente, la Histoire de l,Académie françoise depuis 1652 jusqu,à 1700 del abate d,Olivet (Paris, 1729), uno de los más renombrados académicos de la sabia institución. Por su parte Rejón de Silva contaba con la Histoire du Vicomte de Turenne (Paris, 1749), biografía del que fuera Mariscal General de los ejércitos reales en 1660, compuesta por el abate Raguenet.

Educación (13,2\%). Los impresos de esta naturaleza con destino a la formación moral de niños y jóvenes constituyen un conjunto bien definido, en su mayoría procedentes de la tantas veces mencionada colección de Saurín. La predilección del socio de la Económica de Amigos del País de Murcia y de la Real Academia Geográfico-Histórica de Caballeros de Valladolid está muy visible en su biblioteca, tanto en los libros en español como en francés, no en balde el dueño de aquel nutrido fondo no podía ser ajeno al optimismo pedagógico ilustrado hacia los más jóvenes (Pozo, 1988, p. 275). En sus anaqueles se hallaba un tomo de pequeño formato de "La educación de los hijos", según pensamos una edición en francés de la obra de Locke, De l,éducation des enfants, en alguna de las varias ediciones francesas u holandesas del Setecientos; la versión española, realizada en Madrid a partir de la segunda edición francesa (Amsterdam, 1708), solo vería la luz en 1797, después de la muerte del aristócrata. Avis d,une mere a son fils de la marquesa de Lambert (Paris, 1726) es otro título de esta especialidad donde se expone de una manera renovada la 
ética aristocrática como una conquista personal de las virtudes morales y su proyección en el desempeño de sus deberes sociales (Bolufer, 2015, p. 245). Las obras de la autora francesa fueron vertidas al español por Cayetana de la Cerda tardíamente (1781), en un volumen donde iban incluidas las Advertencias de una madre á su hijo y que no fue reeditado, lo que nos lleva a pensar que su circulación fue más bien restringida; de hecho, la presencia de Lambert en bibliotecas públicas y privadas españolas es muy escasa, aún en aquellas cuyos propietarios podían haber conocido sus escritos en versión original (Bolufer, 1015, p. 262). De carácter didáctico y moral son también la Instruction d,un pere a son fils: sur la manniere de se conduire dans le monde de Dupuy La Chapelle (Paris, 1730) y L,école du monde: ou instruction d,un pere a un fils, touchant la maniere dont il faut vivre dans le monde de Le Noble, una edición en seis tomos, según pensamos la de Amsterdam de 1709, ya que la traducción española fue impresa en dos volúmenes (Madrid, 1745) bajo el título Escuela, ó Ciencia del Mundo para todos estados. De Antoine de Courtin es el Nouveau traité de la civilité qui se pratique en France parmi les honnestes gens, antiguo impreso con siete ediciones parisinas en la segunda mitad del XVII que seguirá siendo editado de manera reiterada en el siguiente. Más moderno en el tiempo es el Essai sur l,éducation de la noblesse de Brucourt (Paris, 1747), cuya edición española con la traducción de Bernardo María de Calzada data de 1792, una vez fallecido el dueño del ejemplar. Por último, L,ecole des moeurs, ou Réflexions morales et historiques sur les maximes de la sagesse del canónigo Blanchard (Paris, 1775), encaminada a formar "las costumbres de la juventud, y el hacer à los hombres más virtuosos y sabios", será traducida por Ignacio García Malo con la recomendación expresa a padres, maestros y ayos de hacerla leer a los niños desde su infancia. ${ }^{16}$ Fuera de la biblioteca del académico Saurín, pero también con el mismo destino educativo, es el Magasin des enfants ou dialogues d,une sage gouvernante avec ses élèves de la première distinction compuesto por Madame Leprince de Beaumont para sus alumnos, ejemplar perteneciente a don Juan Pedro Flores ${ }^{17}$, cuyo hijo Mariano había sido alumno del Seminario de Nobles de Valencia entre 1799 y 1801 (Ruiz, 1980, p. 124). La obra de la pedagoga francesa, la mejor de su producción, recoge temas científicos, geográficos e históricos dentro de una pedagogía moderna que busca el deleite, la curiosidad y el interés del lector al adaptarse a la edad de cada infante (Piquer, 2015, p. 327-329).

Ciencias (14,7\%). La materia científica está conformada por nueve títulos de muy diversa temática por lo que su porcentaje es elevado. La Filosofía acoge dos impresos: De la raison dans l,homme de Etienne Brémont (Paris, 17851787), en seis tomitos en $12^{\circ}$, y del abate Batteux, la Histoire des causes premières, ou expose sommaire des pensées des philosophes sur le principe des êtres (Paris, 1769). En poder del III marqués de Torre Pacheco se hallaban en 1781, al morir su primera esposa, el Dictionnaire raisonné de physique del filósofo naturalista Mathurin-Jacques Brisson (Paris, 1781-1800), junto a una preciosa impresión repleta de grabados al buril con la descripción de máquinas y artilugios procedentes del gabinete de curiosidades de Nicolás Grollier de Servière, ingeniero francés del siglo XVII, dado a la estampa por su hijo. El catálogo de ingenios mecánicos, Recueil d,ouvrages curieux de mathematique et de mecanique, ou description du cabinet de monsieur Grollier, fue editado hasta tres veces en las prensas lionesas y parisinas desde 1719, lo que muestra el éxito del mismo. El ejemplar en poder del aristócrata sería adquirido unos años más tarde (1795) por otro patricio de su entorno, don Jesualdo Riquelme, quien desembolsó por él 30 reales a la testamentaría del marqués. ${ }^{18}$ Algo más gravaso debió de resultarle a Saurín adquirir los siete tomitos del Traite de l'opinion ou Memoires pour servir a l'histoire de l'esprit humain de Gilbert-Charles le Gendre, donde su autor aborda la historia de la Astrología, las Matemáticas y otras ciencias en una impresión veneciana de 1735.

Por la naturaleza técnica de su contenido incluimos en este campo otros tres impresos, todos ellos relacionados con la ciencia militar o al servicio de ella. Es el caso de Les fonctions du capitaine de cavalerie et les principales de ses officiers subalternes de Birac (Paris, 1668), ejemplar en manos del marqués de Beniel en 1727; tenemos noticia de otras impresiones parisinas, aunque la obra fue reiteradamente editada en La Haya a finales del Seiscientos. A la biblioteca de un ilustrado pertenece L,esprit du Chevalier Folard tiré de ses commentaires sur l,histoire de Polybe pour l,usage d,un officier de Main de Maître (Paris, Amsterdam, 1761), en realidad un compendio de los seis tomos de la Histoire de Polybe con los comentarios del militar e ingeniero Jean Charles de Folard repleto de tácticas y estrategias militares (Paris, 1727-1730). En la misma erudita colección encontraba su asiento un libro en $4^{\circ}$ sobre arquitectura militar, compuesto por el abate Deidier, Le parfait ingénieur français ou La fortification offensive et défensive (Amsterdam, 1734), texto reeditado en dos ocasiones que sepamos por las activas prensas de la capital francesa.

Junto a los títulos anteriores computamos un impreso en dozavo de teoría política del siglo XVII acerca de la justificación del golpe de estado por el príncipe como acción política excepcional para la salvación del propio estado. Nos referimos a las Considerations politiques sur les coups d,estat, de Gabriel Naudé editado por primera vez en Roma en 1639 con tan solo doce ejemplares por su carácter casi clandestino (Cavaillé, 2011). Las ediciones posteriores, sacadas de la romana, se sucedieron a lo largo del siglo XVII y en la siguiente centuria.

Religión (8,1\%). El último campo temático es el que aporta un menor porcentaje, un hecho perfectamente explicable si reparamos en que las lecturas religiosas y prácticas devotas requieren, más que otras materias, la 
utilización de impresos en la lengua que le es más propia al devoto lector, a menos que tenga un buen dominio de otro idioma. Aun así, son varios los títulos que menudean en las colecciones analizadas. La condesa del Valle de San Juan disponía de un volumen de oraciones encuadernado "en pasta encarnada en latín y francés", cuya identificación no es posible por la carencia de datos; tan solo podemos señalar que se encontraba ubicado junto a un "Breviario nuebo del Oficio de la Virgen", un tipo de impreso litúrgico fuertemente ligado a la cotidianidad femenina. ${ }^{19}$

En el inventario de otra biblioteca más moderna en el tiempo, la de Flores Navarro, se encuentra otro impreso de devoción, dos tomitos encuadernados en pasta, L, ame élevée a Dieu par les réflexions et les sentimens pour chaque jour du mois del padre Barthélemy Baudrand. El texto del jesuita conoció varias ediciones en francés durante la década de los años setenta, al tiempo que veía la luz la traducción española en las prensas leonesas en 1776 . El mismo lector tenía a su disposición las Figures de La Bible: contenues en cinq cens tableaux, Gravés d,apres les desseins de Raphael, \& des plus grands Maitres, Accompagnés d, une courte Explication pour l,instruction de la Jeunesse (Paris, 1767). La edición estampada por Desprez, Impresor del Rey y del Clero de Francia, va engalanada con 500 calcografías que acompañan el texto explicativo, cuyas iniciales aparecen ornadas xilográficamente por medio de un factotum o taco de madera grabado y vaciado en su interior destinado a acoger la inicial tipográfica correspondiente. El aristócrata Riquelme Fontes conservaba entre sus escasos libros en francés la Bibliotheque ascétique en sentimens des SS. Peres \& des auteurs ecclésiastiques sur les plus importans sujets de la morale chrétienne, ejemplar editado en París entre 1761 a 1769. La obra del agustino reformado Jerome de Sainte-Monique fue estampada en siete tomitos en $12^{\circ}$, valorados en 140 reales por el librero que tasó la biblioteca del noble en 1800 . Por último, contamos con un impreso sobre fenómenos sobrenaturales, Traité historique et dogmatique sur les Apparitions, les Visions \& les Révélations particuliéres del abate Lenglet Du Fresnoy (Paris, 1751), que al parecer interesaba al polifacético escritor y académico de la lengua, Rejón de Silva, en otro tiempo residente en la Corte.

\section{REFLEXIONES SOBRE LOS RESULTADOS}

La precariedad de resultados obtenidos es inseparable de los datos generales de la muestra analizada, ya que de los inventarios con libros (77\%) solo un 18\% acogen algún impreso en lengua francesa. Partiendo de esta exigua realidad, los datos de que disponemos sobre las bibliotecas murcianas del período comprendido entre 1700 a 1811 dibujan un panorama ciertamente pobre por lo que a la posesión de libros en francés se refiere. Pero también es cierto que su presencia será cada vez más visible conforme avanza el siglo, un recorrido similar al experimentado en la incorporación tardía y paulatina de autores franceses traducidos entre los fondos analizados. Es en la década de los cincuenta cuando comienza a detectarse un interés creciente de la elite por aprender la lengua de moda con la incorporación de gramáticas y diccionarios en sus anaqueles, aunque no podemos desechar que la adquisición de tales impresos se encontrase más orientada a la formación de sus hijos que a la propia. Por tanto, el aprovisionamiento de instrumentos de aprendizaje (Sobrino, Núñez, Galmace) no implica necesariamente que llegaran a adquirir un dominio de dicha lengua, aunque su torpe conocimiento pudiera haber sido utilizado como mero artificio social en algún caso. De lo contrario, el grueso de los impresos en francés no se hallaría, como lo está, en manos de unos pocos lectores, representantes destacados de la cultura murciana de finales de siglo. Sin duda, el conocimiento efectivo del francés por parte de Joaquín Saurín y su colega en la Económica de Amigos del País de Murcia desde 1792, Diego Antonio Rejón, les permitió la recepción en su idioma original de un conjunto de impresos en consonancia con sus gustos y/o necesidades lectoras, cosa que no ocurre en el caso de otros académicos como Jesualdo Riquelme o Antonio Fontes Ortega, doctor en Leyes y director de la real institución murciana, dos lectores con claras inquietudes intelectuales, pero que probablemente no llegaran a dominar el francés hasta el punto de querer surtir sus bibliotecas con impresos en aquel idioma. Hay, no obstante, otros dos casos de interés fuera de los círculos académicos que conviene destacar. Nos referimos a los libros de una fémina, la condesa del Valle de San Juan, posible lectora de algún impreso devoto como hemos visto, de igual modo que el regidor Flores Navarro y su familia pudieron acceder a ciertas lecturas religiosas y literarias por su dominio del idioma galo. El resto de los dueños de ejemplares en francés, fuera de los estrictamente destinados al aprendizaje que son la mayoría, parece responder más bien a adquisiciones muy puntuales donde la lectura en imágenes podía solapar, tal vez, la falta de un dominio real de la lengua. Como es natural, este panorama va a marcar la naturaleza de los títulos con una clara hegemonía de los impresos lingüísticos para conocer la lengua tan íntimamente ligada al hombre "ilustrado" de la época, unas "luces" que según refiere el viajero francés Alexandre Laborde solo pudo encontrar, curiosamente, entre los libros de don Jesualdo Riquelme Fontes durante su visita a la capital murciana en los años noventa del siglo XVIII (Viñao, 1997, p. 253).

Esto es lo que señalan los datos, pero no olvidemos las carencias que presentan muchos de los inventarios de la muestra; esas "bibliotecas devaluadas" por diversos motivos e incluso alguna "biblioteca clandestina" pudieron encerrar en su día otro retrato. 


\section{NOTAS}

${ }^{1}$ Archivo Histórico Provincial (A.H.P.) Murcia. Prot. 3336, ante A. López Mesas, s. f.

2 A.H.P. Murcia. Prot. 2702, ante A. Costa Irles, f. 72 r.-73 v.

3 A.H.P. Murcia. Prot. 2753, ante P. Espinosa de los Monteros, f .226 v.

4 A.H.P. Murcia. Prot. 2670, ante J. Leandro Castilblanque, s.f.

5 A.H.P. Murcia. Prot. 3973, ante P. Basilio Villanueva, f. 11v. de los Autos para el inventario de los bienes de doña Inés de Chillerón.

6 A.H.P. Murcia. Prot. 3261, ante J. Jordán Fernández, f. 545 r.-555 v.

${ }^{7}$ Los Diálogos muy apazibles escritos en lengua española y traducidos en francés de Oudin fue publicada hasta siete veces durante el siglo XVII.

8 A.H.P. Murcia. Prot. 2986, ante Esteban González, f.80 v.

9 A.H.P. Murcia. Prot. 2986, ante Esteban González, f.210 v.

${ }^{10}$ Ejemplar de la Universidad complutense de Madrid, Biblioteca Histórica marqués de Valdecilla: M-UC-NOV, BH DER 8724.

11 A.H.P. Murcia. Prot. 3141, ante F. Jiménez Ortega, s.f.

${ }^{12}$ Una nota enmarcada tipográficamente y ubicada por el impresor en la contraportada en la que podemos leer: "Se previene al Pùblico, que los Exemplares de esta Obra que no estuviese rubricados, y firmados de mano del Autor, deben considerarse por supuestos y fraudulentamente impresos. Antonio Galmace (rúbrica)". Ejemplar de la Universidad Complutense de Madrid, Biblioteca Histórica marqués de Valdecilla: M-UC-NOV, BH DER 10882 .

${ }^{13}$ Archivo Histórico Ciudad de Barcelona (A.H.C.B.), Fondo Comercial, ACB-1022. Libro copiador de facturas de la Casa Piferrer, $1790-1804$.

${ }^{14}$ Sobre este particular, la rica biblioteca del valenciano marqués de Dos Aguas, mostraba en 1707 un predominio del italiano en los libros extranjeros, signo de que la expansión del francés todavía no se había producido entre la nobleza. CATALÁ SANZ, 1992, p. 22, nota 29.

${ }^{15}$ Para ello hemos consultado, fundamentalmente, el Catálogo Colectivo del Patrimonio Bibliográfico Español (C.C.P.B.), más los catálogos de la Biblioteca Nacional de España y la Biblioteca Nacional de Francia.

${ }^{16}$ Prólogo del traductor. Edición de Madrid: Blas Román, 1786.

17 A.H.P. Murcia. Prot. 2384 ante J. Mateo Atienza, f. 524 r.

18 A.H.P. Murcia. Prot. 4222, ante J. Mateo Atienza. Cuentas del administrador de Riquelme, f.1220 r.

19 A.H.P. Murcia. Prot. 2986, ante Esteban González, f. 209 v.

\section{BIBLIOGRAFÍA}

ABASCAL PALAZÓN, J.M. y CEBRIÁN FERNÁNDEZ, R. José Vargas Ponce (1760-1821) en la Real Academia de la Historia. Madrid: Academia de la Historia, 2010.

AGUILAR PIÑAL, F. La biblioteca de Jovellanos (1778). Madrid: C.S.I.C, 1984.

AGUILAR PIÑAL, F. Le livre français dans la bibliothèque de Jovellanos. Dix-huietième siècle, 1984, vol. 16, p. 405409.

AGUILAR PIÑAL, F. Entre la escuela y la universidad: la enseñanza secundaria en el siglo XVIII. Revista de Educación, no extraordinario, La Ilustración en la Educación Española, 1988, p. 225-244.

ÁLVAREZ BARRIENTOS, J. Ser negro en la republica literaria española del siglo XVIII. En: Le Guellec, M. (ed.). El autor oculto en la literatura española: Siglos XIV a XVIII. Madrid: Casa de Velázquez, 2014, p. 93-106.

ARIAS DE SAAVEDRA ALÍAS, I. Libro, lectores y bibliotecas privadas en la España del siglo XVIII. Chronica Nova, 2009, vol. 35, p. 15-61.

ARRIBAS, N. Los diálogos lucianescos de Francisco Sobrino. Enthymema, 2010, vol. 2, p. 23-58 [en línea]. Disponible en: doi: https://doi.org/10.13130/2037-2426/761.

BASTIN-HAMMOU, M. Introduction. Brumoy, pédagogue et passeur du théâtre grec. Anabases, 2011, vol. 21, p. 2741 [en línea]. Disponible en: <https:// journals.openedition.org/anabases/2137> [Consulta: 13 de octubre de 2019]

BOLUFER PERUGA, M. Pedagogía y moral en el siglo de las Luces: las escritoras francesas y su recepción en España. Revista de Historia Moderna, 2002, vol. 20, p. 251-292 [en línea]. Disponible en: doi: 10.14198/RHM2002.20.10.

BOLUFER PERUGA, M. Una ética de la excelencia: Cayetana de la Cerda y la circulación de madame de Lambert en España. Cuadernos de Historia Moderna, 2015, vol. 40, p. 241-264 [en línea]. Disponible en: https://doi.org/10.5209/ rev CHMO.2015.v40.49170.

CAVAILLÉ, J.P. Naudé, la prudence extraordinaire du coup d,État. Les Dossiers du Grihl, 2006 [en línea]. Disponible en: <http://journals.openedition.org/dossiersgrihl/4807> [Consulta: 10 de febrero de 2020]

CATALÁ SANZ, J.A. La biblioteca del primer marqués de Dos Aguas, 1707. Valencia: Universidad de Valencia, Departamento de Historia Moderna, 1992.

CHAPARRO SÁINZ, A. y ARTOLA RENERO, A. El entorno de los alumnos del Real Seminario de Nobles de Madrid (1727-1808). Elementos para una prosopografía relacional. En: IMÍZCO BEUNZA, J.M. ${ }^{a}$ y CHAPARRO SÁINZ, A. (coords.). Educación, redes y producción de elites en el siglo XVIII. Madrid, Silex ediciones, 2013, p. 
177-200 [en línea]. Disponible en: <https://halshs.archives-ouvertes.fr/halshs-00918430v2/document> [Consulta: 13 de abril de 2020]

RAMÓN ESQUERRA, R. Juicios de Saint-Évremond sobre España y la Literatura española. Bulletin Hispanique, 1936, vol. 38, n 3, p. 353-363.

GARCÍA BASCUÑANA, J.F. Materiales para la enseñanza del francés en España: aproximación a los manuales publicados entre los siglos XVI y XX. Revista interuniversitaria de Formación del Profesorado, 2005, vol. 19, nº 2, p. 129-144.

GARCÍA BASCUÑANA, J.F. ¿Con qué libros se aprendía francés en España en 1808? Anales de Filología Francesa, 2008, vol. 16, p. 73-85

GARCÍA BASCUÑANA, J.F. Lecturas españolas del Telémaco de Fénelon en los siglos XVIII y XIX. En: GIMENO PUYOL, M. ${ }^{a}$ D. y VIAMONTE LUCIENTES, E. (coords.). Los viajes de la razón: estudios dieciochescos en homenaje a María-Dolores Albiac Blanco. Zaragoza: Institución Fernando el Católico, 2015, p. 275-289.

GARCÍA CUADRADO, A. Una biblioteca del Barroco: la colección bibliográfica de los marqueses de Beniel en 1710. Historia y Memoria de la Educación, 2017, vol. 6, p. 421-457 [en línea]. Disponible en: https://doi.org/10.5944/hme.6.2017.17214.

GARCÍA CUADRADO, A. (2017b). Entre el Barroco y la Ilustración: tres bibliotecas murcianas del Antiguo Régimen. Revista General de Información y Documentación, 2017, vol. 27, nº 2, p. 383-407 [en línea]. Disponible en: https://doi.org/10.5209/ RGID.58210.

GASPAR GALÁN, A.; CORCUERA MANSO, J.F. y FIDEL, J. La gramática francesa de Baltasar de Sotomayor (Alcalá de Henares, 1565). Zaragoza: Prensas de la Universidad de Zaragoza, 2015.

INFANTES, V. Las ausencias en los inventarios de libros y de bibliotecas. Bulletin Hispanique, 1997, vol. 99, $\mathrm{n}^{\circ}$ 1, p. 281-292.

JALÓN, M. Sobre la cultura técnica impulsada por Carlos III: la Encyclopedia Metódica como empresa ilustrada. Investigaciones históricas: época Moderna y Contemporánea, 1997, vol. 17, p. 101-136.

LÉPINETTE, B. Heureux ceux qui s,instruisent en se divertissant (Télémaque, liv.12). À propos de Télémaque en Espagne (fin XVIIIe-début XIXe siècle). Documents pour l,histoire du français langue étrangère ou seconde, 2003, vol. 31, p. 102-116.

LÉPINETTE, B. Traduction et histoire. Quaderns de filología: Estudis lingüístics, 2003, vol. 8, p. 60-91.

LLANOS GÓMEZ, R. El padre Isla, traductor de obras francesas. En: Lengua y cultura: estudios en torno a la traducción. Actas de los VII Encuentros Complutenses en torno a la traducción, vol. II. Madrid: Universidad Complutense, Instituto Universitario de Lenguas Modernas y Traductores, 1999, p. 335-342.

MEDINA ARJONA, E. Las traducciones de Charles Rollin y su lugar en la bibliografía pedagógica española del siglo XVIII. En: LAFARGA, F. (ed.). La traducción en España (1750-1830): lengua, literatura, cultura. Lleida: Universidad de Lleida, 1999, p. 233-242.

PEDRAZA GRACIA, M.J. Lector, lecturas, bibliotecas...: el inventario como fuente para su investigación histórica. Anales de Documentación, 1999, vol. 2, p. 137-158.

PEÑA VELASCO, C. de la. Aspectos biográficos y literarios de Diego Antonio Rejón de Silva. Murcia: Consejería de Cultura y Educación, 1985.

PÉREZ, J. Cisneros, el cardenal de España. Madrid, Taurus, 2014.

PIQUER DESVAUX, A. El periplo literario de Leprince de Beaumont: del cuento maravilloso a la historia ejemplar. En: GIMENO PUYOL, M. ${ }^{a}$ D. y VIAMONTE LUCIENTES, E. (coords.). Los viajes de la razón: estudios dieciochescos en homenaje a María-Dolores Albiac Blanco. Zaragoza: Institución Fernando el Católico, 2015, p. 326-336.

PÉREZ PICAZO, M. ${ }^{a}$ T. La pequeña nobleza urbana en la transición del antiguo al nuevo régimen, 1750-1850. El caso de Murcia. En: Les noblesses européennes au XIXe siécle. Roma: Universitá di Milano y École Française de Rome, 1988, p. 473-528.

POZO PARDO, A. del. El Despotismo Ilustrado y la educación primaria. En: Simposium Internacional sobre Educación e Ilustración: dos siglos de reformas en la enseñanza. Madrid: Ministerio de Educación y Ciencia, Centro de Publicaciones, 1988, p. 270-300.

RIDER, R.E. El experimento como espectáculo. En: ORDÓÑEZ, J. y ELENA DÍAZ, A. (coords.). La Ciencia y su público: perspectivas históricas. Madrid, C.S.I.C., 1990, p. 113-146.

RUBÍN DE CEBALLOS, A. Índice último de los libros prohibidos y mandados expurgar: para todos los Reynos y Señorios del Católico Rey de las Españas. Madrid: Sancha, 1790.

RUIZ NAVARRO y RUIZ DEL RIQUELME, M. Caballeros seminaristas del Real Seminario de Nobles de San Pablo de la ciudad de Valencia (1670-1836) nacidos en Murcia o en su provincia. Murgetana, 1980, vol. 57, p. 117-134.

SUÁREZ GÓMEZ, G. La enseñanza del francés en España hasta 1850. ¿Con qué libros aprendían francés los españoles? Edición y notas de Juan F. García Bascuñana y E. Juan Oliva. Barcelona: Promociones y Publicaciones Universitarias, 2008. 
SUPIOT RIPOLL, A. Un diccionario bilingüe (español-francés, francés-español) del siglo XVIII. El Diccionario Nuevo de Francisco Sobrino. En: LAFARGA, F. y DONAIRE FERNÁNDEZ, M.L. (coords). Traducción y adaptación cultural: España-Francia, p. 493-502. Oviedo: Universidad de Oviedo, Servicio de Publicaciones, 1991.

SUPIOT RIPOLL, A. Les manuels de Français Langue Étrangère en Espagne entre 1648 et 1815. Approche bibliographique. En: GARCÍA BASCUÑANA, J.F.; LÉPINETTE, B. y ROIG, C. (eds.). L, universalité du français et sa présence dans la Péninsule Ibérique. Actes du colloque de la sihfles tenu à Tarragone, Université Rovira i Virgili, 1995. Paris: sihfles, (Documents pour 1'Histoire du Français Langue Étrangère ou seconde 18), 1996, p. 313-329.

VIÉMON, M. Le traitement de e dans un système de prononciation figurée du français au XVIIIe siècle: la "Coleccion de las falsas reglas" de Galmace. Çédille, revista de estudios franceses, 2013, vol. 9, p. $511-527$ [en línea]. Disponible en: < https://cedille.webs.ull.es/9/29viemon.pdf> [Consulta: 20 de marzo de 2020]

VIÑAO FRAGO, A. El Colegio-Seminario de San Fulgencio: Ilustración, liberalismo e Inquisición. Áreas. Revista de Ciencias Sociales, 1986, vol. 6, p. 17-48.

VIÑAO FRAGO, A. Murcia. Bulletin Hispanique, 1997, vol. 99, n 1, p. 243-256.

ZUILI, M. César Oudin y la difusión del español en Francia en el siglo XVII. En: BRUÑA CUEVAS, M.; CABALlOS BEJANO, M.a; ILLANES ORTEGA, I.; RAMÍREZ GÓMEZ, C. y RAVENTÓS BARABGÉ, A. (coords.). La cultura del otro: español en Francia y francés en España. Sevilla, Universidad de Sevilla, 2006, p. 278-289.

ZUILI, M. La larga historia del Tesoro de las dos lenguas española y francesa de César Oudin (ed. Prínceps, 1607): entre autoridad e innovación. Hipogrifo, Revista de Literatura y Cultura del Siglo de Oro, 2016, vol. 4, $\mathrm{n}^{\circ} 1, \mathrm{p}$. 271-288. 